\title{
The concept of hyperenculturation: An example from a Swedish research school
}

\author{
Anna Petersson \& Catharina Sternudd \\ Department of Architecture and Built Environment, Faculty of Engineering (LTH), \\ Lund University, Sweden
}

\begin{abstract}
The aim of this paper is to discuss how research schools with a structured programme and targeted profile may make it difficult for doctoral students to expand the academic role. Our paper is based on material collected in a questionnaire given to doctoral students enrolled at a Swedish research school in architecture. In this questionnaire we found three areas - openness to other disciplines and practices; support for different communicational channels; and various research approaches and methodologies - where a certain divergence could be observed between what the students perceived was important for their educational development, and how well their needs and wishes were met by the research school and its extended learning environment. We also found that the doctoral students valued the teaching experience they gained, and wished they had been able to teach more. In order to shed light on a process of enculturation that we see as potentially leading to a narrowing learning culture, we introduce and discuss the concept of what we call 'hyperenculturation.'
\end{abstract}

Keywords: research school, doctoral education, architecture, enculturation, learning culture, disciplinary belonging

\section{INTRODUCTION AND AIM}

\section{Introduction}

During the last decades, Swedish doctoral education has, in general, become more formalised and structured (Holmström, 2018). A defined and collective research culture with direct ties to industry has been promoted, for example, as embodied by a number of research schools in Sweden (Degerblad \& Hägglund, 2002). Research schools have also been set up as a response to society's need for research-educated personnel, and as a means of enhancing the standing of an academic subject by strengthening its ties to research (Persson, 2007). Several of these objectives were crucial for the start of a national research school in architecture in Sweden: an area of doctoral education that was seen as under-developed and in need of a collective and structured approach with strengthened ties to societal needs (Formas, 2006).

Architectural research in Sweden has been described as having a humanistic content with high social relevance. In 2006, a report from the Swedish Research Council Formas found that contemporary Swedish architectural research was relevant to applied contexts, even though its content had become more specialised. However, as Formas noted, the theoretical and

\footnotetext{
*Correspondence: Anna Petersson, anna.petersson@arkitektur.lth.se 
epistemological foundations of this research had not developed to a commensurable extent. In 20II, the four Swedish university departments of architecture, at the Faculty of Engineering (LTH), Chalmers University of Technology (CTH), the Royal Institute of Technology (KTH) and Umeå University (UMU), were granted funding from Formas for a national research school in architecture - ResArc - with the aim of providing an educational programme for doctoral students in architecture that is able to meet current needs in the industry, the profession and the research community, as well as in society. At the same time, two strong research environments also received five-year grants for strengthening architectural research, and working towards greater relevance for the discipline and its application to architectural practice and the broader societal context. In order to support the traditional high standing of architectural research in Sweden, as well as expand its theoretical foundations to ensure its relevance as a contemporary research context, five target areas were defined for ResArc.

The research school should: I) provide an educational programme with courses, seminars, symposia and workshops as educational formats that meet current needs; 2) work to promote a learning culture that encourages broad theoretical investigations in connection with experimental and practice-oriented methods, including a close relationship with the architecture profession; 3) lay the basis for an integrated communicational approach in $\mathrm{PhD}$ projects, seeking to interface with international peer-reviewed journals, public debates, specialised thematic publishing, experimental publication forms, and exhibitions; 4) foster contacts between, on the one hand, architectural researchers, doctoral students and supervisors and, on the other hand, members of other research disciplines and representatives of the architecture profession, in order to increase the quality of inter-and transdisciplinary research; and 5) support dissemination of research activities and academic production in the area of architectural research (Swedish Research School in Architecture, 20II).

In 2015, three years after the inauguration of the research school, a survey was conducted to evaluate Swedish doctoral education in architecture in general, with a special focus on departmental research environments, the national research school and its extended research networks. This questionnaire revealed that standards in some of the targeted areas, such as the educational programme in architectural research, had improved considerably due to ResArc's courses, seminars, conferences and other networking activities. The epistemological and theoretical foundation of the work of doctoral students in architecture, which was seen as underdeveloped in the Formas evaluation (2006), had been improved by ResArc. At the same time, it was found that there was still a shortfall in other target areas, such as openness to other disciplines and practices; support for different communication channels; and various research approaches and methodologies, all of which could be related to an extended research arena. Another emerging issue, not specifically targeted by the research school, was that there was felt to be insufficient support for those engaged in departmental tasks such as teaching.

Aim of the paper

The aim of this paper is to discuss how the format of research schools, with a structured programme and targeted profile, may make it difficult for doctoral students to expand the academic role. After analysing the seemingly weaker spots of the Swedish Research School in Architecture's learning environment, we will introduce the term 'hyperenculturation'. This term is used in the discussion to illustrate how a well-intentioned process of enculturation can lead to an overly rigid learning culture, which potentially may impede a broader and more varied research community and practice. 


\section{BACKGROUND AND THEORIES}

\section{ResArc: Swedish Research School in Architecture}

ResArc was inaugurated in February 2012 as a national research school in architecture at the same time as two strong research environments; all three were funded by the Swedish Research Council Formas. It is a research school for doctoral students coming from the five-year architecture degree programmes in Sweden. The four Swedish university departments of architecture and the two strong research environments are all involved within ResArc at both decision-making and working levels. As an example of the latter, the four departments take turns to host a series of doctoral courses that recur in two-year cycles. Most of the senior researchers engaged in supervising doctoral students in the research school, through courses or doctoral supervision, have also been involved in research activities through the two strong research environments. To date, three cycles of doctoral courses have been completed and a fourth cycle is running as a non-funded collaborative continuation of the research school. Since the start of ResArc in February 2012 and as of April 2020, thirty-two doctoral students have passed through the research school and defended their dissertations at one of the four departments of architecture in Sweden.

\section{Architecture education}

Education in architecture has an artistic and practice-based approach, with focus on both process and product (Sternudd, 2013). It could be described as "learning "for" disciplinary practice rather than learning "about" a discipline or subject' (Webster, 2008, p. 64). The undergraduate and graduate levels of the architecture programme are grounded in a master-and-apprentice learning situation, where students sketch, model and discuss together with their supervisors to reach a final design solution, which is then assessed by a review panel of teachers and experts (Webster, 2005). At post-graduate level, the doctoral students in architecture commonly work alone writing monographs in a person-driven educational situation. Knowledge acquisition at doctoral level is mainly geared towards use in academia, with the $\mathrm{PhD}$ students learning to master the skills needed as a researcher (cf. Degerblad \& Hägglund, 2002, p. I6). ${ }^{\text {I }}$ The master-and-apprentice learning situation could be seen as being continued in the relationship between the supervisor and doctoral student (Lee, 2008), but the student's research is also continuously being measured against the wider academic community through courses, compulsory seminars, and academic conferences.

It is, however, not only in the educational context and learning situation that students develop their skills. Both formal and informal socialisation processes affect learning and the forming of disciplinary identities (Webster, 2008; Holmström, 2018). For example, the four departments of architecture in Sweden all teach architecture and have doctoral students in architecture, but they have slightly different research and educational profiles and, consequently, varying research and educational milieus and values. It is interesting to notice how new students, both under-graduate and post-graduate, seem to assimilate the different approaches and how they soon become part of each milieu's respective 'culture'. To understand more about this adaptive learning process we will briefly turn to what is often called 'enculturation'.

\section{Enculturation}

Stemming from the study of socio-cultural aspects of learning and capital (Vygotsky, 1978; Bourdieu, 1993), the term enculturation implies that students are dependent not only on their own endeavour for reaching a certain level of academic success, but also on their specific background 
and the framework where their learning process takes place. In academic discourse, the term enculturation has been widely used to describe the process whereby students gain access not only to a set of tools for acquiring and assessing knowledge, but also to a set of cultural norms related to ways of behaving, writing, making, acting, socialising and even dressing (e.g. Webster, 2005; Mattsson, 20I5; Anderson, 20I7; Walker \& Yoon, 20I7). Enculturation is hence an embodied practice, which relates to multisensory modes of meaning-making and senses of belonging (Thyssen \& Grosvenor, 2019). It is important to point out here that for some students the path to gaining access to a specific group and to certain facets of knowing is more an act of assimilation than actual enculturation - that is, the students adopt 'instrumentalist attitudes of compliance' just to fit in and pass the exams (Godfrey, 2008). At under-graduate level assimilation or adaptation might be sufficient for acquiring the expected learning outcomes, whereas at post-graduate and occupational level individuals need to both recognise and internalise the given values and norms of their academic discipline if they are to succeed (Godfrey, 2008; Walker \& Yoon, 20I7). To reach the competence level of an expert researcher in a specific discipline requires both an institutionalisation in, and a critique of, the norms and culture of this disciplinary practice (Langemeyer, 2019).

The enculturation process includes elements of apprenticeship. As Lee states (2008, p. 272, with reference to Leonard, 200I, p. 98), 'achieving a PhD is about becoming a member of an academic discipline'. To achieve this, the doctoral student must become aware of, get acquainted with, and find the keys to, not only the culture of a specific department, but also a community of discipline, and a country/civilisation, in order to get 'epistemological access' (Lee, 2008, p. 272; cf. Anderson, 20I7). Looking at why individuals fail to gain access to - in other words, fail to become 'encultured' in - a community of discipline, Lee mentions struggles between supervisor and doctoral student that can be political on several levels (2008, p. 272). There may also exist a hierarchy of norms relating to academic culture, for example, between departments, research schools and supervisors, which pushes the student to make different academic choices during the different stages of their doctoral education (Geschwind \& Melin, 2016). Doctoral students can also be hindered by their own capabilities or the actual opportunities open to them to make strategic choices and position themselves in academic practice as well as in the broader socialisation process (Anderson, 2017; Walker \& Yoon, 2017). The existence of both explicit and implicit standards and codes for judging merit and ability, with familiarity and similarity being seen as guarantors of smoother social interaction, is one type of such exclusion (Essed \& Goldberg, 2002, p. 107I). This is noticeable also in the informal socialisation process, which is transmitted via social meetings and patterns of acting, and can be an especially strong force for doctoral students working alone (Holmström, 20I8).

In this paper we will be discussing a type of enculturation process characterised by distinctly structured and targeted access, which we anticipate may lead to a learning culture that strengthens similarity rather than encouraging diversity (cf. Essed \& Goldberg, 2002; Mattson, 20I5). In order to move on to this debate, however, we need first to take a closer look at some of the questionnaire responses.

\section{MATERIALS AND METHODS}

\section{The ResArc doctoral student survey questionnaire}

Data was collected using a web-based survey questionnaire, with a web link to the questionnaire being sent via email to all doctoral students in architecture currently registered at the four 
departments of architecture in Sweden (at LTH, CTH, KTH and UMU) participating in ResArc $(\mathrm{n}=73)$. The sender of the email was the ResArc doctoral programme based at the Department of Architecture and Built Environment at LTH. The purpose of the survey questionnaire was, as stated in the invitation letter, to collect information on how the support and service provided by ResArc were received by the doctoral students. Further aims were to elicit ideas as to how the research school could be improved, to plan for future collaboration on doctoral education, and to support further careers for holders of $\mathrm{PhDs}$ in architecture. In other words, the survey questionnaire was not initially intended as a tool for research on the outcome of ResArc, but rather for investigating the development of the research school in particular, and of architectural doctoral education in general. We do, however, think that our reflections on some of the questionnaire responses could support the continuation of the research school and its doctoral education, by providing a theoretical contextualisation of the outcome of ResArc's educational programme. Gaining further in-depth knowledge on the possibly over-developed enculturation discussed in this text would, however, require additional studies, which we tentatively discuss towards the end of the paper.

As supervisor and researcher you have two different roles that can be hard to both keep and tell apart, for the supervisor/researcher as much as for the doctoral student. Supervisors and course leaders involved in running the research school's doctoral programme are also part of the two strong research environments in architecture supported by Formas. Even though the questionnaire promised confidentiality and that the anonymous responses would be analysed as a group, this double role of the supervisor/researcher might have led doctoral students to answer the questionnaire in a way that wouldn't affect their future academic career, or their possibilities of securing a faculty position. The unclear sender/reader function might also be one of the reasons for the relatively low rate of responses to the questionnaire: 33 doctoral students $(45 \%)$ answered the questionnaire. The response rate might hence indicate a non-response bias, which means that the results are not necessarily generalisable.

\section{Findings and analysis}

The questionnaire was designed to assess the doctoral students' study environment in general, with particular focus on the support and service provided by the research school. In order to allow for mixed methods analysis, it contained both Likert scale questions and open-ended freetext questions, amounting to a total of twenty-nine main questions. For the present paper, we chose to analyse three sets of scale questions and two free-text questions, the answers to which showed that there was a discrepancy between how important students felt various services offered by ResArc and its extended learning environment to be, and how much of those services were provided to them. In our selection of these questions, as well as in the analysis of the responses, we have opted for a mix between a quantitative and a qualitative approach (Morgan, 2013/2017).

The three scale questions selected were located under the overarching main question: What level of importance do you attach to the following PhD services and to what extent are they provided by ResArc? Thirteen services were specified and, for each one, two five-point Likert scales ranging from not important (I) to very important (5) and not provided (I) to well provided (5) were applied. We selected questions where a certain divergence between mean scores for perceived importance and provision could be found. The questions are: Support for cooperation with other research disciplines (importance 4,4 and provision 2,6); Support for collaboration with architecture and urban practice (importance 4,0 and provision 2,4); and Support for a communicational approach towards journals, debates, publishing and exhibitions (importance 4,3 and provision 
$2,7)$. The rate of responses varied slightly: 27 students responded to the question concerning importance and 25 answered the question on provision in each set of questions. On the basis of the actual number of respondents in each case we derived the mean score. What emerged was that for some of the respondents there was a perceived importance of openness towards other research disciplines, to the architecture and urban design occupation, and to the wider public, and a perceived lack of support for these issues. For a visual representation of the scale question responses we analysed, see the tables below.

Table I. Perceived level of importance (left) and provision (right) regarding 'support for cooperation with other research disciplines'

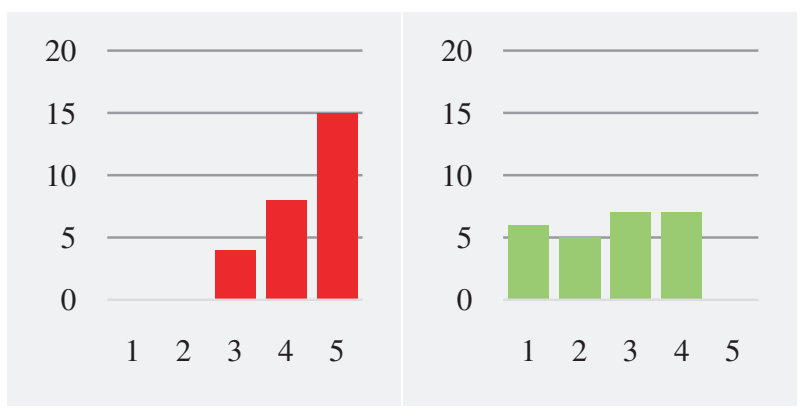

Table 2. Perceived level of importance (left) and provision (right) regarding 'support for collaboration with architecture and urban practice'

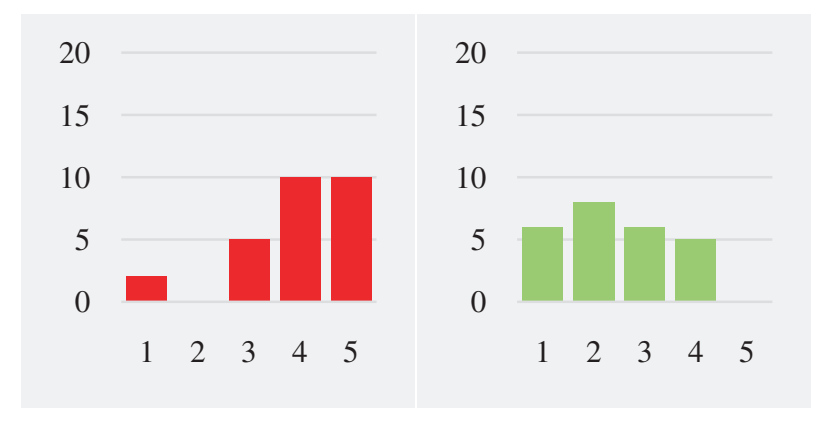

Table 3. Perceived level of importance (left) and provision (right) regarding 'support for a communicational approach towards journals, debates, publishing and exhibitions'

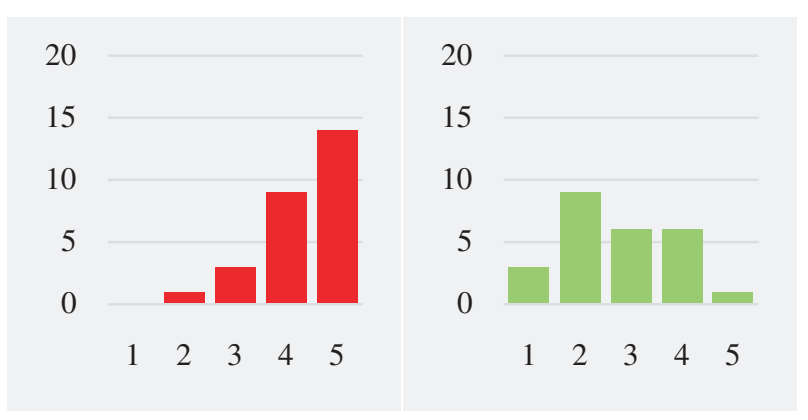




\section{Anna Petersson \& Catharina Sternudd}

The questionnaire also contained questions requiring a text response in the form of shorter phrases or single words. Responses to two of these questions added to our interpretation of the students' perceived importance of, versus lack of, support offered by ResArc and its extended learning environment. The questions are: Which learnings/skills/experiences of your doctoral studies do you personally value the most?; and Which learnings/skills/experiences are you missing? We analysed the free-text responses to these questions by looking both for common themes and for qualitative variations and contradictions within these themes. The composition of the quotations below represents the different viewpoints that were found. ${ }^{2}$

A recurring theme in the responses was the appreciation of, and a desire for, exchange between doctoral students, international researchers, researchers from other disciplines, societal stakeholders and the architecture and/or planning professions. This was expressed through phrases such as:

[I value] 'Meeting and discussions with other PhD colleagues during coursework.'

[I value] 'Involvement in international research groups with many senior scientists.'

[I value] 'Opportunities to engage with colleagues, both within the discipline, but especially

outside of the discipline. Also the opportunity to engage with non-academics, "stakeholders"

within the city, part of social movements, etc.'

[I value] 'Reaching outside of my field of research to apply my findings in real cases.'

'I miss interaction with other $\mathrm{PhD}$ students that might lead to transdisciplinary collaborations.’

Another theme that emerged was the valuing of and, in some cases, a need for, artistic and practice-based research and varied methodological training:

[I value] 'Learning about how design skills can be used in research.'

[I value] 'Artistic research skills.'

[I value] 'Creativity in research methods and methodology.'

'I miss a true support for artistic and design based research.'

[I miss] 'Discussion about how practice and research can be combined.'

[I miss] 'An introduction to archival-type research.'

[I miss] 'More methodological training (to feel more sure in this, as well as exploring a greater variety).'

'I miss discussion with researchers that master qualitative methods.'

[I miss] 'Working with GSI mapping and more digital mapping methods and tools.'

Some students also commented on how they felt they would benefit from more support for different types of research communication, which they felt was lacking:

'The most valuable experience [...] is how to present your research and thinking internationally [...]'

[I miss ] 'Routines for publishing in journals.'

[I miss ] 'Academic writing as a format for my developing, transdisciplinary, emerging field of study...'

[I miss ] 'Writing courses for artistic and architectural research.'

[I miss ] 'How to write (artistic) articles, how to present alternatively (not only powerpoint presentations) at seminars/conferences.' 
There were also responses that expressed both the worth of being able to participate in teaching and a desire for guidance in developing teaching skills:

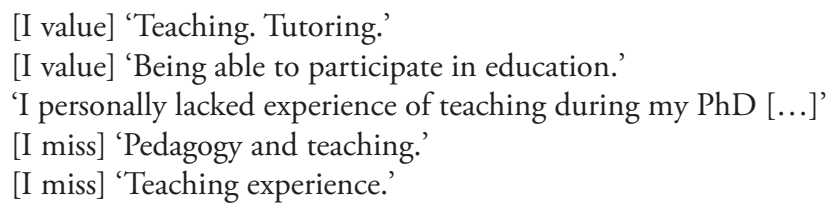

\section{DISCUSSION}

An emerging need for variation, communication and teaching

ResArc's doctoral student survey indicates that the students are reasonably satisfied with their study environment in general, and that they do appreciate the services and support provided by the research school. The overall impression is that most of the doctoral students see themselves as very well integrated in the culture of architectural research - the collaboration with peer doctoral students and the integration in a wider national and international architectural research community and practice is highly appreciated and valued. The ambition of the research school and its course structure has, however, also been to offer guidance on a wider variety of research approaches and publication modes. It seems that an awareness of this ambition has reached the doctoral students responding to the questionnaire, in that they appreciate and value this element. On the other hand, it also appears in the questionnaire responses as if this ambition has not been realised to a satisfying degree.

What we investigate in this paper is a perceived importance of, and emerging need for, openness to other research disciplines, for linking research to (artistic and design) practice, for varied methodological training, and for wider research communication and dissemination. These needs were identified by the Formas evaluation (2006), but had not been fully met at the time of the 2015 survey. In the questionnaire responses we were also made aware of the students' appreciation of, and desire for, teaching experience and teacher training, a desire which had not yet been met in 2015 .

The weaknesses identified could have been down to a lack of experience in these kinds of issues at the four departments of architecture, but this is not actually the case. Many supervisors involved in the national research school have their own experience of the kinds of aspect involved: transdisciplinary research with high societal relevance, varied methodological training, artistic and practice-based research, dissemination in international scholarly media and exhibitions, and both teacher training and teaching experience. These directions or channels of research, dissemination and education seem, however, to have been overshadowed when it comes to passing them on to the doctoral students - perhaps owing to the weight assigned to theoretical and epistemological depth, or maybe because more dominant research approaches have been absorbed by the doctoral students at the departmental level (Geschwind \& Melin, 20I6). This would not be particularly surprising, since enculturation, which is basically a positive and necessary aspect of both doctoral education and academic development, works that way. That is, to become a member of a specific academic community the student needs to incorporate the prevailing skill-set (including research methods, theories, writing and publication styles), as well as the given norms and ideological foundations of that academic discipline, in order to gain 'epistemological access' to it (Lee, 2008, p. 272; cf. Anderson, 2017). 
Another contributing factor to the discrepancy between $\mathrm{PhD}$ students' needs and wishes and what was provided by ResArc could be the research school format in itself, in that its structured programme, limited time frame for courses and profiled research orientation may make outreach to other disciplines and practices difficult to manage. Further, the process of disciplinarisation in the participating departments and the research school's strong disciplinary focus may have reinforced each other, resulting in an academic 'cloning culture' (cf. Essed \& Goldberg, 2002). To look closer at this type of strong but narrowing learning culture we will now turn to the concept of what we call 'hyperenculturation'.

\section{Hyperenculturation}

A positive process of enculturation gives the doctoral students access to the academic discipline in which they are to develop their research approach and, in the future, perhaps also secure a faculty position. This can be achieved through the introduction of the students to the community of their discipline and research environment, as well as to departmental activities such as teaching. A negative process of enculturation can occur when the cultural field of research is unintentionally too clearly demarcated, thus shutting out important and relevant possible expansions, and shutting in research findings and experiences that could be valuable for the educational field as well as the wider academic community.

The concept of hyperenculturation opens for a discussion that highlights how a discipline is both a product of, and a reproducer of, a cloning culture (Essed \& Goldberg, 2002, p. IO8I). It is important to mention this here, since the field of architectural research still has few subjectspecific international peer-review journals to publish in, and also a limited number of research foundations to apply for funds from, both for individual research projects and for a continuation of the research school and the two strong research environments. Taken together, this makes outreach to a wider research community both an important opportunity and a crucial task to take on for the discipline of architectural research. It is also important to draw attention to the double academic role of researcher and teacher, which is a vital part of academia, especially in academic subjects with a strong base in vocational training. The researcher/teacher role could further encourage comprehensive ties between architectural theory and practice, and hence give students tools with which to widen both the architecture profession and the academic discipline of architectural research from within (Kopljar, Nilsson \& Sandström, 20I8).

A main objective of the research school ResArc is, among other aims, to strengthen Swedish architectural research through theoretical and methodological development. An explicit ambition is also to support transdisciplinary collaboration and cooperation between researchers in architecture and the architecture and urban design professions (Swedish Research School in Architecture, 20II). In line with this, a conference was arranged in 2016 to encourage collaborative approaches and writing among the doctoral students. A course on contemporary didactics in architecture education was also developed and held in 2016. This course provided opportunities for doctoral students and lecturers in the field of architecture to gain an overview of teaching and learning in higher education, as well as a thorough understanding of contemporary approaches to architecture education.

The fact that collaborative approaches and teacher training were introduced by the end of the first doctoral students' four years of study might be seen as leading to a reversed-funnelling learning process (cf. Hartman, 1998/2004, p. 28I). This could be expected to reinforce the discipline of architectural research and support a tight research community. Having a thorough understanding of the research discipline to which one belongs, as well as of one's own role in 
that community, before engaging in educational tasks or reaching out to other disciplinary and practice-based fields, could also be seen as an advantage in terms of specific competence and scholarly confidence. The reversed-funnelling approach might, on the other hand, counteract any impulse to widen the discipline of architectural research from within, and also reduce the chances for future employment and collaborations both within and outside of academia, since where a reversed-funnelling approach is in place the widening and outreaching processes are expected to occur when the doctoral students and their projects are already firmly rooted in the current disciplinary context. For fear of transgressing the borders of the invisible demarcations in the dominant research culture, the doctoral students might hesitate to reach out to remote and/or adjacent possible fields of reference and transdisciplinary collaboration.

Choosing instead to adopt a funnelling learning process, starting in common interdisciplinary research-school courses is, however, not in itself a solution to the problem of dominant disciplinary cultures (Geschwind \& Melin, 20I6). In the later and more supervisor-dependent phase of doctoral studies, when $\mathrm{PhD}$ students are exposed to the disciplinary norms of their home departments, the socialisation process can gradually shift focus (Geschwind \& Melin, 20I6, pp. 24-25). When comparing one's own research discipline, including its methods and theories, with that of others in a transdisciplinary educational setting, the boundary between different disciplines can also become clearer, which may unintentionally strengthen one's own sense of disciplinary belonging and impede self-critical engagement (Geschwind \& Melin, 2016, p. 24; cf. Essed \& Goldberg, 2002, pp. I080-IO8I).

Research schools are complex learning environments, with expectations and requirements coming from both supervisors and home departments as well as the research school management. For a doctoral student, finding meaning in the approved knowledge and establishing a sense of disciplinary belonging, yet at the same time breaking away from established practice, may be especially difficult in this type of setting (cf. Langemeyer, 2019; Thyssen \& Grosvenor, 2019). Since Swedish doctoral students in architecture generally work on their own, quite often on research subjects that they are alone in mastering, their need to belong to a community of those who share a discipline may perhaps be especially strong (cf. Holmström, 20I8). Our analysis suggests that the seemingly strong disciplinarisation brought about by the research school and its participating departments might have made it harder for the $\mathrm{PhD}$ students to develop a broad knowledge of the research field, its dialogue with architectural and urban practice, and with the public more generally (cf. Faculty of Engineering, Lund University, 2007/2019). As a term for this complex and highly focused enculturation process we tentatively propose hyperenculturation.

Although this paper is based on a limited amount of data from a single survey questionnaire, the findings presented here still call attention to a potentially narrowing learning culture. To carry out an in-depth examination of this phenomenon would, however, require additional studies. This could involve looking closer at a larger selection of questions in the ResArc survey questionnaire, as well as collecting further research material via new studies. Qualitative in-depth interviews with former doctoral students could add insight into the learning culture discussed in this text, and possibly also provide material for new directions in research into the concept of hyperenculturation. Another important addition would be to follow up on the research school cohort over time, by sending out the same questionnaire again five years after the collection of the material discussed in this text. This would allow for a study of the enculturation process over time, where possible changes in the socialisation process could be pinpointed and examined. And if a whole new set of questions were added to such a study, 


\section{Anna Petersson \& Catharina Sternudd}

specifically targeting the phenomenon of enculturation at departmental and research-school level, this could further highlight the different disciplinary cultures in these educational environments, as well as their mutual influence on each other.

\section{Running research schools as externally funded projects}

In response to a Formas call in 20I6, ResArc applied for further funding to strengthen the school's ties to the industry as well as to other professional and societal actors, but was not granted any further economic support. The research school still continues as a non-funded collaboration between the four departments of architecture in Sweden, but how long this unfunded partnership will endure is currently an open question, given that the number of doctoral students decreased after the funding ceased.

The educational format of research schools in Sweden, which receive their government research funding via strategic research foundations (such as Formas and Vetenskapsrådet), has largely been considered successful in terms of time- and cost-effectiveness and quality of teaching, and for offering a supportive social context (Degerblad \& Hägglund, 2000; Persson, 2007). In general, increased cross-disciplinary cooperation, primarily at a national level, has been seen as a positive effect of Swedish research schools, along with strengthened ties between $\mathrm{PhD}$ education and the industry (Degerblad \& Hägglund, 2000). As argued in this text, these latter potential benefits of national research schools seem, however, not to have been sufficiently taken advantage of by ResArc at the time for our study.

A number of possible weaknesses in Swedish research schools have also been detected. Some of these weaknesses relate to the subject that is discussed in this text, for example, having a clear research-school profile may make an expansion of the academic role difficult (including making ties between research and undergraduate education). Despite good intentions to establish close connections to the profession, the ties between research schools and the industry can still be weak and, since funding has to be continuously applied for, the plans for the future of research schools and their research collaborations tend to be uncertain (Degerblad \& Hägglund, 2000, pp. 5I-60). Additionally, having too many higher education environments within one research school can leave the smaller environments with only a few doctoral students, which leads to inadequate and unstimulating local research milieus that cannot be compensated for by the overarching research school (Persson, 2007, pp. 2I-22).

The problem of running research schools in the same way as any other externally funded research project is evident in the way it puts a hold on developmental and pedagogical possibilities that could enrich the schools' academic milieus, including both a critical mass of doctoral students and a variety in the courses offered. It takes time to build up a good research school, and it also takes time, continuous and long-term work, and stable financing to establish constructive relations with the industry and other societal actors (cf. Degerblad \& Hägglund, 2000, p. 55). The insecure future of research schools, together with their targeted profiles and structured programmes, can also make the task of teaching as a doctoral student difficult to manage. This is something that needs to be acknowledged and dealt with, especially in subjects where a strong connection between vocational training and academic research is sought after and valued: in the research community, the profession and society.

\section{ABOUT THE AUTHORS}

Anna Petersson is a Senior Lecturer at the Department of Architecture and Built Environment, LTH, Lund University. She has specific experience in research on ritual and cultural space and 
applied aesthetics, with an interdisciplinary and phenomenographic approach. Anna teaches at the undergraduate and graduate levels of the Industrial Design Programme and she is involved in postgraduate education in her home department.

Catharina Sternudd is a Senior Lecturer in Architecture at the Department of Architecture and Built Environment, LTH, Lund University. Her primary area of research is urban design, with a special focus on environmental support for sustainable everyday practices. She also coordinates the research network Urban Arena at Lund University, which aims to support transdisciplinary research related to sustainable urban development.

\section{REFERENCES}

Anderson, T. (2017). The doctoral gaze: Foreign PhD students' internal academic discourse socialization. Linguistics and Education, 37, 1-10. doi:10.1016/j.linged.2016.12.001

Bourdieu, P. (1993). The field of cultural production: Essays on art and literature (R. Johnson, Ed.). Cambridge: Polity Press.

Degerblad, J.-E., \& Hägglund, S. (2000). SSF:s forskarskolor. En utvärdering av Stiftelsens för Strategisk Forskning satsning på forskarskolor. Stockholm: Stiftelsen för Strategisk Forskning/Högskoleverket.

Degerblad, J.-E. \& Hägglund, S. (2002). Tradition och förnyelse i svensk forskarutbildning. Högskoleverkets rapportserie 2002:26. Stockholm: Högskoleverket.

Essed, P., \& Goldberg, D. T. (2002). Cloning cultures: The social injustices of sameness. Ethnic and Racial Studies, 25(6), 1066-1082. doi:10.1080/0141987022000009430

Faculty of Engineering, Lund University. (2019). General syllabus for third-cycle studies in architecture TEAAAFOO (Reg no. U 2019/104). Lund: Author. (Approved 2007 and amended 2019.) Retrieved from: https:/www.lth.se/fileadmin/lth/lthhandboken/utbildningforskning/forskarutbildning/ Arkitektur_2019-05-08_eng.pdf

Formas (2006). Evaluation of Swedish architectural research 1995 - 2005. Report 7:2006. Stockholm: Author.

Geschwind \& Melin (2016). Stronger disciplinary identities in multidisciplinary research schools. Studies in Continuing Education, 38(1), 16-28. doi:10.1080/0158037X.2015.1000848

Godfrey, E. (2008). University education: Enculturation, assimilation or just passengers on the bus? Paper presented at the $11^{\text {th }}$ Pacific Rim First Year in Higher Education (FYHE) Conference, Hobart, Australia. Retrieved from: http://fyhe.com.au/past_papers/papers08/FYHE2008/content/pdfs/ 6c.pdf

Hartman, J. (2004). Vetenskapligt tänkande: från kunskapsteori till metodteori (2nd ed.). Lund: Studentlitteratur. (Original work published 1998.)

Holmström, O. (2018). Ensamarbetande doktoranders perspektiv på forskarutbildning och doktorandtillvaro: Ämnesmässig ensamhet, den informella socialisationens kraft och erkännandets betydelse. Högre utbildning 8, 14-29. doi:10.23865/hu.v8.1138

Kopljar, S., Nilsson, E. \& Sandström, I. (2018). Expanding architecture: Critical perspectives from within a school of architecture. Paper presented at LTHs 10:e Pedagogiska Inspirationskonferens, Lund, Sweden. Retrieved from: https://www.lth.se/fileadmin/lth/genombrottet/konferens2018/B3_Kopljar_ etal.pdf

Langemeyer, I. (2019). Modelling undergraduate research and inquiry-based learning - Why enculturation matters. Outlines - Critical Practice Studies, 20(1), 71-96.

Lee, A. (2008). How are doctoral students supervised? Concepts of doctoral student supervision. Studies in Higher Education, 33(3), 267-281.

Leonard, D. (2001). A woman's guide to doctoral studies. Buckingham: Open University Press.

Mattsson, T. (2015). 'Good girls': Emphasised femininity as cloning culture in academia. Gender and Education, 27(6), 685-699. doi:10.1080/09540253.2015.1069796 


\section{Anna Petersson \& Catharina Sternudd}

Morgan, L. (2017). Integrating qualitative and quantitative methods: A pragmatic approach. London: SAGE Publications. (Original work published 2013). Retrieved from: http://methods.sagepub.com.ludwig. lub.lu.se/book/integrating-qualitative-and-quantitative-methods-a-pragmatic-approach

Persson, G. (2007). Utvärdering av forskarskolor finansierade av Vetenskapsrådet 2001 - 2006. In Samverkan, forskarskolor och nätverk - kartläggning av särskilda villkor och bidragsformer inom utbildningsvetenskap (pp. 11-22). Stockholm: UVK/Vetenskapsrådet.

Sternudd, C. (2013). Studieuppgift 2. Course assignment presented in the course Forskarhandledning introduktion at the Centre for Educational Development (CED), Lund University, Lund, Sweden.

Swedish Research School in Architecture (2011). Application posed to the Swedish Government Research Council Formas (Code: 2011-6722-18784-160).

Thyssen, G. \& Grosvenor, I. (2019). Learning to make sense: Interdisciplinary perspectives on sensory education and embodied enculturation. The Senses and Society, 14(2), 119-130.

Vygotsky, L. S. (1978). Mind in society: The development of higher psychological processes (M. Cole, V. John-Steiner, S. Scribner \& E. Souberman, Trans.). Cambridge, MA: Harvard University Press.

Walker, J. \& Yoon, E (2017). Becoming an academic: The role of doctoral capital in the field of education, Higher Education Research \& Development, 36(2), 401-415. doi:10.1080/07294360.2016. 1207616

Webster, H. (2005). The architectural review: A study of ritual, acculturation and reproduction in architectural education. Arts and Humanities in Higher Education, 4(3), 265-282. doi: $10.1177 / 1474022205056169$

Webster, H. (2008). Architectural education after Schön: Cracks, blurs, boundaries and beyond. Journal for Education in the Built Environment, 3(2), 63-74. doi: 10.11120/ jebe.2008.03020063

\section{NOTES}

I. In a survey of alumni doctoral students from the four departments of architecture in Sweden carried out in 2014 by the ResArc Doctoral Programme at LTH, the question regarding current employment reveals that $56 \%$ of the former doctoral students are university employees, while $17 \%$ are employed by the government or a municipal council, $7 \%$ by a private consulting company or architect's office, I3\% by other employers, and $7 \%$ are unemployed.

2. Minor language errors have been corrected by the authors. 